\title{
Information Systems Field at the Forks: Relish Diversity or Perish
}

\author{
Bob Travica \\ University of Manitoba, Canada
}

btravica@ms.umanitoba.ca

\begin{abstract}
This article discusses the relationship between the informing science and information view of organization. Both approaches are described, similarities and differences between them demonstrated, and the contribution of the latter to the former discussed.
\end{abstract}

Keywords: Informing science, information view of organization, information, communication, information technology, organization theory, cognitive theory

\section{Introduction}

This article discusses the relationship between informing science and information view of organization (IVO). Both of these approaches endorse different disciplines that are orthogonal or tangent to the study of information systems (IS), while departing from slightly different theoretical premises. Information view of organization was recently introduced (Travica, 2003) as a new way of looking at organizations from the IS perspective. IVO aims at bringing together the streams of research that have traditionally addressed information and information technology (IT) independently from each other. Another integration direction concerns strengthening the links between the IS field, organization theory and cognitive theory. IVO intends to advance theory of IS and provide a guidance for practicing managers and professionals for understanding issues pertaining to the intersection of ISs and the organizational context. In addition to conceptual works on IVO, the framework has been initially tested in several case studies.

Informing science was introduced by Cohen (1999). Informing science also aims at a theoretical integration with communication and organization theory as primary targets. The main goal of informing science is defined in terms of ensuring that needs of organizational users of information are effectively served. Informing science intends primarily to provide a practical guidance to organizations. The framework of informing science has been advanced through recent efforts of its proponents.

In this article, I will describe premises, goals, and the scope of IVO and informing science, criti-

Material published as part of this publication, either on-line or in print, is copyrighted by the Informing Science Institute. Permission to make digital or paper copy of part or all of these works for personal or classroom use is granted without fee provided that the copies are not made or distributed for profit or commercial advantage AND that copies 1) bear this notice in full and 2) give the full citation on the first page. It is permissible to abstract these works so long as credit is given. To copy in all other cases or to republish or to post on a server or to redistribute to lists requires specific permission and payment of a fee. Contact Publisher@InformingScience.org to request redistribution permission. cally appraise the latter one, and define similarities and differences between the two approaches. The article will conclude with a proposal on how IVO can be used to broaden informing science.

\section{Information View of Organization}

IVO has been introduced in several recent articles (Travica, 2003, 2004, 
2005a, 2005b). IVO is a conceptual and analytical framework intended to aid in explaining and managing ISs in organizations. IVO draws on the IS field, organization/management theory, and cognitive theory. In particular, IVO aims at bridging the gaps between the IS fields and organization theory. In its multidisciplinary and reconciliatory approach, IVO sides with informing science (Cohen, 1999) and similar recent initiatives (Orlikowski \& Barley, 2001; social informatics). The background rationale is that organization at various levels (firm, group, individualtask/process) is presumed to be the natural habitat for ISs. By bridging the gap, both sides can gain: the IS field can better contextualize and situate its key concept of IS, and organization theory can gain better insight into modern ISs that typically are not differentiated from other organization technologies, knowledge, organizations of work, and management techniques. In addition, IVO intends to bridge a gap between different academic streams of research addressing ISs. These are split into two camps. One focuses on IT while obscuring information issues (e.g., the way information systems are usually taught in business schools in North America). The other camp does the opposite (e.g., schools of library and information science and the descendents of these). IVO insists on studying both information and IT. In addition, in approaching the IT artifact, IVO takes a more specific look that accounts for systems functionality, user interface and other material particulars. The background assumption is that the time has come to contribute to understanding IT beyond the accustomed black boxed, abstract approaches based on proxy measures (e.g., the time expended in using IT) (see Orlikowski \& Iacono, 2001). An exhaustive discussion of these issues is in Travica (2005b).

IVO uses a broader understanding of information, IT, and organization. In particular, IVO conceives information as an informing agency, that which shapes human cognition. This concept is consistent with lexical definitions of information that draw on the Latin root of the word "information.” This informing agency can take on different forms, starting with data-sense data as well as data as human-created artifacts (letters, numbers, image, sound). Data are processed and interpreted with assistance of knowledge in human mind, which results in meaning. Different knowledge bases can engender different meanings of the same data. Meaning, in turn, can add to the previous knowledge. IVO takes interest in data, meaning, and knowledge as forms of information that are interrelated although clearly distinguishable from each other in terms of location, complexity, portability, truth value, etc. For example, data can reside both inside and outside of the human brain (e.g., in paper records and in electronic databases), while meaning and knowledge cannot be external to the brain.

Knowledge can be externalized in various representations that are nothing but organized data. Only these data can be communicated. The same applies to meaning: it cannot be simply "transmitted" but only communicated via data. Forms of information differ in terms of the truth value as well. While data and meaning are susceptible to formal metrics of truth applicable to various frameworks (e.g., formal logic, and measurement systems), knowledge evades such precise validations. For example, competing theories based on opposed premises can coexist. This is the modus operandi of physics and other natural sciences as much as it is of social sciences (which sometimes are unjustly blamed for their "inexact nature"). Implications of this differentiating between different forms of information are paramount for the study of ISs in organizations. Beyond its simplest form of data, information becomes a complex cognitive phenomenon that is prone to subjective variation and evades precise validation. Also, transmission/exchange models of communication may pertain only to data and not to the higher forms of information.

With respect to understanding IT, IVO strives to reach beyond abstract approaches that the mainstream IS research exhibits. This research often operates with opaque operationalizations of IT in the form of surrogate measure (e.g., the frequency of usage, or the amount of investment in it). Or even less enlightening, IT is treated as a black box (see Orlikowski \& Iacono, 2001). These approaches neglect particular characteristics of particular types of IT and/or corresponding ISs. An- 
other sort of abstraction occurs with sociologizing of IT, when IT is "dissolved" in social relationships as is the case with recent institutional approaches (e.g., Orlikowski, 1992). In contrast to these abstractions, IVO pledges for reach accounts on material characteristics of IT, including functionality, usability of user interface, capabilities and limitations. Research on design, adoption, use, and evaluation of ISs should aim at understanding how these characteristics of particular technologies interact with particular users in the organizational context. To illustrate with an example from a study I currently run based on the IVO approach (further, a utility company case). Modules of an Enterprise Resource Planning (ERP) system for human resource (HR) management were released in the utility company under a tight schedule, and with some half-baked functionality. One such feature concerns the fact that data entry screens "flash" every time the user enters a piece of data. These screens run within a browser window, which in turn runs on a corporate intranet. The screen "flashing" has been identified as a big shortcoming ("annoying," "disturbing," etc.) by a number of users belonging to different departments and hierarchical positions. An interesting finding is that many users do not know why the "flashing" happens, while those claiming to know why provide differing explanations. In any case, the flashing fact appears to be a factor in the system adoption. Another finding is that the "flashing" has been cited as a downside along with other usability issues as well as with process-related issues.

The cited process issues seem to be of a particular significance for the HR management applications studied. Namely, the applications were accompanied with a change in the process of approving work hours and monetary expenses. In the past, the process combined electronic and paper records. A clerk would enter time and expenses data by using then available HR modules in the ERP system, and then the approval would be done either by the same clerk or by a manager, who would use a printout of electronic records. With the new HR modules, clerks have become limited to the role of data entry, while approval procedures are now reserved for managers. However, my investigation so far has shown that managers may not be willing to adopt the new process. One justification made is that the system "unloads more work" on managers (which indeed is true), and that this work does not add value. Another justification is that the system disables delegating approval responsibility down, and just allows it to be delegated across (both true). The users-complainers argue that this method makes it impossible to ensure that the approvals are done in absence of managers (e.g., when they attend meetings or are on a business trip or vacation). Since even the most trusting person cannot be assigned to do online approvals if such a person is not flagged with management responsibility in the system's database, approvals can only be made by other temporarily assigned managers who may not be well informed for performing this task (e.g., they reside on a remote location). My investigation reveals that radical rejections of the system typically cite this new work process as a significant problem. In short, these examples indicate advantages of using a rich account of IT that IVO advocates. The important facts of screen "flashing" (refreshment) and changed approval process may play a significant part in explaining the system adoption, evaluation, and use.

Organization is a different entity for an interpretive, modernist or postmodern theorist (Clegg, Hardy, \& Nord, 1996; Hatch, 1997; Westwood \& Clegg, 2003). How one understands information, communication and IT, their relationships, and organizational roles is likely to depend on the ontology of organization used. For example, for a modernist thinker an organization is usually a system with clear goals, while information, communication and IT are instruments for achieving the goals. All these aspects as well as the progress toward goals are susceptible to measurement, contend the modernist. Contrary, postmodernists break with the assumption of a driving organizational paradigm and can show tolerance for different paradigms and traditionally marginal topics, such as emotion and esthetics. Thus, organizations can also be viewed as organisms, brains, mental prisons, the context of chaos, and so on. On their part, interpretivists may turn to political and cultural/symbolist perspectives, and render the roles of information, communication and IT in this light. So for example, a system adoption failure may be interpreted through the 
prism of job security, hidden political agendas, and communication of unintended meanings (Sarker \& Lee, 1999).

IVO advocates an ontological pluralism. Rather than being an intellectual fad, I believe that a pluralist approach is needed in order to make sense of the complexity challenging contemporary organizations (Clegg \& Hardy, 1996; Davidow \& Malone, 1992; Handy, 1993; Hatch, 1997; Heckscher \& Donnellon, 1994; Peters, 1992; Thietart \& Forgues, 1995). Bureaucratic organization is not the only organizational design, and it has been challenged by the network, virtual, adhocratic and other new designs (Travica, 1999). Organizational environments also change, become global in scale, and engender unprecedented levels of uncertainty and ambiguity. Owing to the electronically networked character of today's global economy, the social forces we create evade our comprehension and control (Castells, 1996). In this situation, it appears to be misleading to portray organizations exclusively in terms of a machine, parts of which are information and IT, and that effectiveness can be reached by greasing well and occasionally repairing the organizational machine.

In brief, there is a correspondence between conceptualizations of information, communication, IT and organization, and IVO advocates a broader approach to each of these and to their relationships.

\section{Topical Areas in IVO}

IVO incorporates several topical areas that are shown in Table 1 . These topics have been discussed in several articles (Travica, 2003, 2005b; also see the articles cited separately in the following discussion).

Table 1. Topical Areas in IVO

\begin{tabular}{|l|l|}
\hline IVO Topic & $\begin{array}{l}\text { Individual cognition, individuals as creators and users of infor- } \\
\text { mation and of ISs. }\end{array}$ \\
\hline $\begin{array}{l}\text { Homoinformaticus } \\
\text { Informatics) }\end{array}$ & $\begin{array}{l}\text { Group cognition, decision making, collaborative work and group } \\
\text { support systems. }\end{array}$ \\
\hline Infostructure & $\begin{array}{l}\text { Patterns of relationships between information segments and the } \\
\text { arrangement of IT that complement social structure. }\end{array}$ \\
\hline Infoprocesses & $\begin{array}{l}\text { Interrelated information activities that altogether deliver an out- } \\
\text { come to a customer. }\end{array}$ \\
\hline Infoculture & $\begin{array}{l}\text { Beliefs, behaviors and artifacts that are related to information } \\
\text { and IT. }\end{array}$ \\
\hline Infopolitics & $\begin{array}{l}\text { Power, agendas, and fight/flight behaviors related to information } \\
\text { and IT. }\end{array}$ \\
\hline Infoeconomics & The value and costs of information and IT. \\
\hline IS Management Areas & $\begin{array}{l}\text { Issues/challenges/problems of design, adoption, use, and evalua- } \\
\text { tion of IS approached from the stance of IVO aspects above. }\end{array}$ \\
\hline
\end{tabular}

From the IVO perspective, individual organizational members are creators and users of both information and ISs. This omnipotent individual is called homoinformaticus. That individuals are creators of information follows from IVO's concept of information discussed above. Whereas it is 
trivial that individuals create data (e.g., documents), IVO points out that individuals are also agents of developing meaning and knowledge. It is important to understand these processes on both the sender and receiver side in various communication settings in organizations. For example, while a system designer may believe that "logical" closing steps in an online approval procedure are "Send" and then "Save and Close," users may find this order to be counterintuitive (as one of the respondents in the utility company case put it: "You first save a record, then you email it”). Different knowledge perspectives engender different understandings of proper order of steps. Technologists are concentrated on a big picture of the business process (view data, make decision and record it in the system, send the decision to the payroll and the employee, permanently store new data, exit the application). What matters first is that a decision is made and sent. In contrast, users apply experience from using other applications, perhaps somewhat fueled by incomplete trust in technology (view data, make decision and record it in the system, permanently store the decision, send the decision, exit the application). What matters first is to make and save the decision. Another facet of the creativity of organizational members refers to IS development life cycle. Users can provide a valuable input for designing and implementing a system, as exemplified in participatory design (Iivari \& Lyytinen, 1999), and they can modify systems functions in the adoption stage. The homoinformaticus segment of IVO draws heavily on individual and cognitive psychology.

The next topic in IVO refers to groups approached from a cognitive perspective. This is the area of group informatics or groupomatics. Specifically, of interest are the processes of perception, learning memorizing, retrieval, and thinking/problem solving. These topics parallel topics studied within individual cognitive psychology. Cognitive psychology reminds us again of a differentiated character of information. For example, perception involves both external stimuli and internal mental activity (Eysenck and Keane, 1995, pp. 80-81). An individual gathers sense data, organizes it, and, with help of previous knowledge (mental imagery, schemas, mental models), attributes a meaning to it. Perception is, thus, a process of active creation of meaning. IVO implements these assumptions in the concept of homoinformaticus and raises them again in the area of group informatics. IVO also builds on the remarkable research in the area of group support systems (e.g., Ciborra, 1996; Nunamaker, Briggs, Mittleman, Vogel, \& Pierre, 1996/7; Turoff, Hiltz, Bahgat, \& Rana, 1993). Another point of interest is recently advanced research into transactive memory and collective mind (Shaila \& Saunders, 1995; Shepherd, Briggs, Reining, \&Yen, 1995).

The next set of topical areas within IVO draws on centering the well-known views of organization around information and IT. The classical structural view is modified into infostructure (Table 1). For example, Weber's (1946) concept of hierarchy (the levels of graded authority) is modified into "levels of information and IT." The background assumption is that structuring of information and IT is a necessary condition for the social structuring of organizations. For example, an ERP system provides different views of data and different data manipulation capabilities depending on the hierarchal position of users. The rights of data access are a segment in the entire bundle of rights that define a level in organizational hierarchy. For instance, decision making authority of management levels strongly depends on the former rights. In addition to the vertical dimension, infostructure includes a horizontal, formalization, and centralization aspect.

The part of organizational culture that relates to information and IT is the domain of infoculture. Davenport and Prusak (1997) have previously proposed a concept of information culture but narrowed it down to "behaviors and attitudes that express an organization's orientation toward information" (p. 84). In an infoculture, assumptions, values, symbols, and rituals have a clear, narrower focus rather than the broad one that pertains to the concept of organizational culture. An apparent example of infoculture is core beliefs and behaviors characterizing the use of modern ISs (e.g., the etiquette of an email system). Early studies of computer mediated communication discovered that people behave differently when using email (e.g., Kiesler, Siegel, \& McGuire, 
1984). An aberration from usual social norms and an expression that is more honest were some of the changes (for better or for worse) discovered. Although organizations may try to channel this infoculture according to the mainstream organizational culture, it appears that every new communication technology/system repeats the story of email. A tension between paper and electronic forms of information can characterize values, attitudes and work practices in older organizations that make a transition toward modern ISs. This is true of the utility company implementing HR modules in the ERP system. Another example of infocultural artifacts, is indicated by the company's managers that tend to characterize the method of online approvals as a penetration of clerical (non-value adding) work into their turf. Symbolically, they associate the system to inappropriate work and waste of time.

Infopolitics refers to issues of power, agendas, and fights/flights that concern organizational information and IT. Making the core of contemporary organizations, information and IT constitute high political stakes. In the organizational literature, it has long been maintained that control over professional knowledge can be a source of power (Crozier, 1964; Pfeffer, 1981). Barley (1986, 1990) related power changes to knowledge of manipulating new computer-based medical technology, and Zuboff (1984) identified a possibility of power gains on the side of professionals who adopted new digital IT in different kinds of organizations. In a case study of a festival venue in Canada, I found that a monopoly of knowledge on organizing and management represented the main lever of power (Travica, 2005a). Yet, another example comes from our utility company, where new HR applications prevented clerks from making decisions they used to make before with a blessing of supervisors. Thus, the new system reasserted the formal distribution of decision making authority. Indeed, organizations can be highly politicized contexts (depending on their design). If so, words and other communication codes are more likely to have double than single, denotative meanings, and one can seek in vain to achieve the fidelity of information beyond the sheer level of data.

IVO recognizes significant merits of the process view of organization and incorporates it into its coverage through the concept of infoprocess. IVO's focus is on information components of business processes and fully-fledged infoprocess that consist solely of information activities. In accord with the notion of business process, infoprocess refers to interrelated information activities that deliver an outcome to a customer (cf. Hammer and Champy, 1993). IVO takes interest in various aspects of the process approach to organizations, including coordination theory (Malone and Crowston, 1994), business process reengineering (Hammer and Champy, 1993), new organizational forms, and the study of ERP systems. Infoprocesses exist at different levels, ranging from processes that manipulate data at the micro level of interconnected tasks to macroorganizational and inter-organizational infoprocesses. There are connections and dependencies between infoprocesses at different levels. The highest level infoprocesses give rise to a new organizational design - the virtual organization, since they interpenetrate organizational boundaries. In a case of Internet service in a four-star hotel, I discovered that a dysfunctional infoprocess at the micro level unraveled the related upstream infoprocess, with the end result being a dissatisfied process customer - the guest (Travica, 2004).

Finally, infoeconomics refers to valuing and costing issues pertaining to information and IT. This aspect is important because it relates directly to organizational economics and other aspects of the bottom line of organizations. While the cost side yields to inquiry (e.g., Snyder \& Davenport, 1987), the valuing of information and IT is bound to paramount challenges. What is the economic contribution of meaning and knowledge to a particular organizational task or to the organizational bottom line (profit, quality of service)? In spite of a number of methodologies tried, success of teasing out the contribution of information are rather meager, particularly when one tries to reach beyond intangible benefits (e.g., more complete and timely information) to tangible benefits (monetary payoffs). The core of the problem may be in the character of the information phe- 
nomenon. Information appears to be one of those things whose value can be assessed only retroactively at use time. Knowledge accumulated through education is a typical example: students acquire knowledge a priori (before the fact), and understand its value a posteriori (after the fact). The payback from IT or more appropriately IS also evades analysis based on tangible figures. This is so in spite of certain properties of IT/IS that reverse classical economic laws, such as the law of diminishing returns.

One apparent reason for the challenges of valuing is that, in a typical scenario, IT/IS are in service of information; they are the means of manipulating data that can become meaning and knowledge. Therefore, the problem of valuing IT/IS boils down to valuing information. Another challenging issue is a variety of contexts of using IT/IS. IT may not be deployed directly in production but in support of functions that are not considered value adding (e.g., accounting control, HR management, communications).From this perspective, IT/IS does not add value to the organizational output, although it could help avoid or reduce administrative labor costs (a tangible benefit). When IT/IS is deployed in information industry whose output-partly or entirely -is information (e.g., mass media, education, financial and insurance industries), tracking tangible payoffs from IT is difficult to do beyond the level of data transactions. For example, to what extent and how a financial information system helps a bank analyst to design new bank services is a question for empirical research rather than an evaluation task susceptible to formalized metrics. In contrast to these examples, more automated organizational contexts dispose IT/IS closer to other production technologies, or to commodity (Carr, 2004) whose benefits may be easier to track.

The level of analysis poses another sort of challenge in valuing IT/IS and associated information. If benefits from these show up at the task level, they may not necessarily occur at the process or organizational level of analysis. The reverse is also true: process benefits may not show at the level of each individual participating task. Further, the same IT/IS can result in more benefits in one organization than in another; organizational context (structure, culture management) can make a difference (Brynjolfsson \& Hitt, 1998). At the level of economic sectors, no contribution of IT/IS to the office work productivity has been detected yet. This phenomenon, known as "IT productivity paradox" (Roach, 1987), has been a subject of a heated discussion in recent years.

All these are important and interesting issues that chart the territory of infoeconomics. IVO provides a framework for analyzing relationships of infoeconomics with other IVO aspects and with the bottom line (organizational economics or effectiveness in some other respect). For example, one may investigate how infoculture does/can contribute to changes in infoprocesses that, in turn, have effect on infoeconomics and economics. Illustrating by the case of the utility company: an infoculture of paperless office ties into new infoprocesses of managers' online approvals of employees' time and expenses, which improves infoeconomics (faster data flows, higher integration of electronic data on human resources). But, impacts on organizational economics are uncertain, since savings in clerical work (for approvals) are countered by expenditures in managerial work.

The IVO topics or aspects discussed so far represent the backdrop for certain aspects of managing ISs. These are the issues of design, adoption, use, and evaluation of IS approached from the stance of IVO aspects above. So, in order to understand and manage IS adoption, one needs to look into IVO aspects that are relevant for the given situation. Establishing this relevance is an empirical question and it cannot be determined beforehand. This follows from the character of IVO: it is a framework, not a finalized research model.

In summary, IVO places information and IT at the nexus of organization. IVO uses a differentiated concept of information, strives to bring for rich accounts of IT, and operates with different models of organization. IVO consists of seven topical areas reflecting the organizational context, and intersects these with issues of IS design, adoption, use, and evaluation. 


\section{Informing Science}

The term informing science and the related framework has been introduced by Cohen (1999). Drawing on Mason and Mitroff's (1973) work, Cohen defines informing science as a set of fields that have the goal to "provide their clientele with information in a form, format, and schedule that maximizes its effectiveness" (p. 4, 5; the emphases are original).

The theoretical foundation of the informing science framework consists of three models: Shannon and Weaver's (1949) mathematical model of communication, Leavitt's (1965) model of organization, and a three level-analysis (Cohen, 1999). The Shannon and Weaver model of communication was developed with the purpose of explaining data communications in telephone networks. Over time, the model was adopted by social researchers for studying human communication. The model defines and relates several concepts: sender, signal, channel, noise, information, and receiver. The sender element (e.g., a phone set) transmits a signal over a channel (e.g., a wire) to a receiver element (e.g., another phone set). While traveling, the signal loses some energy (e.g., due to resistance of the wire), which is conceived as noise or entropy. To compensate for the loss, new energy has to be added. This energy is conceived as negative entropy or information. Therefore, information is the measure of negative entropy that is needed for accurate transmission of electrical signals. In the later use of this model by social and behavioral scientists, there is a significant shift in the concepts and their relationships (more below). Cohen (1999) suggests that the model is useful for understanding that communication is synonymous with informing; in turn, informing reduces uncertainty on the receiver's side. Similarly, the purpose of informing science is to design, manage, and use communication systems that effectively inform/reduce uncertainty.

The Leavitt (1965) model of organization and organizational change conceives of organization in terms of people, task, technology, and structure. Organization members perform on organizational tasks, while using different technologies and following rules, lines of reporting and other structural properties. In addition to providing analytical lenses on organization at a micro level of analysis, the purpose of this model is to alert on a brittle character of organizational equilibrium. Leavitt (1965.) has assumed that the four aspects of organization are inter-related so that a change in any of them causes changes in others. Equilibrium (stability or, in Leavitt's terms, a "freeze state”) is difficult to achieve. Once any aspect is tilted off balance ("unfrozen”), the other aspects follow the suit, and changes trigger new changes. It takes management effort to bring the organization system back to equilibrium, or to "re-freeze" organization and, thus, make the changes achieved permanent. The third basis of the informing science framework refers to different levels of analysis or abstraction.

Drawing on the theoretical basis described above, Cohen (1999) defines three components of the informing science framework: informing environment, delivery system, and task-completion system. The backbone is Shannon and Weaver's (1949) model (furthermore, the model), which is combined with elements from the other two theoretical bases. Specifically, informing environment corresponds to the sender part, and it is approached at three levels of analysis - the use of existing informing practices, creation of new standard practices of informing, and creation of new types of informing practices (e.g., using an IS for sending information, designing a new IS, and creating a new type of IS). (Note: The term "practice" is mine.) Delivery system refers to transmitting information, which can be done by means of an IS, and this corresponds to communication channel in the model. Finally, task-completion system refers to accomplishing a task with help of information received, which corresponds to the receiver part in the model. The provision of information for accomplishing tasks is informing process' reason for existence. Therefore, the primary goal of this modeling and of informing science in general is to inform clients (those at the receiving end of information, or user of ISs) in an effective way. 
Informing science is a new framework, and attempts at advancing it have been made quite recently (e.g., Gackowski, 2005; Roussev and Rousseva, 2004). Gackowski (2005) also draws on Shannon and Weaver's model and explores characteristics of data and information (i.e., meaning) in the business context (e.g., accuracy, timelines, completeness, and economic aspects). In a critical appraisal of the original informing science framework, Gackowski points out that information does not only reduce uncertainty but can increase it as well; an example is information on environmental threats to an organization. He also proposes a set of characteristics to extend the concept of information used in informing science. In addition, Roussev and Rousseva (2004) have used propositions from the informing science framework to analyze the process of software engineering (this area of computer science largely overlaps with what is called systems analysis and design in the IS field). It could be said that many ideas the authors have discussed parallel system development methodologies that involve users more deeply. These range from participatory design and other methodologies created in Scandinavia (Iivari \& Lyytinen, 1999) to today's efforts to the same end (Majchrzak, Beath, Lim, \& Chin, 2005).

\section{Informing Science and Information View of Organization}

This section will provide a critical appraisal of informing science and an analysis of the relationship between informing science and IVO. The first apparent characteristic of Cohen's (1999) framework on informing science is its interdisciplinary focus. A primary motivation behind informing science is in integrating various streams of research in the IS field. Another key characteristic is that informing science takes a practitioner's approach to ISs (see Table 2, the Informing Science column). Put another way, informing science manifests a consulting and service orientation. This is indicated in the teleological definition of informing science is-the purpose of delivering effective information is framed as the key definitional point. This characteristic also indicates that information is a central concept in the framework, although an explicit conceptualization of information is missing. In addition, the definition of informing science is broad enough to encompass (a) various organized contexts in which informing can take place and (b) various categories of clients.

The Leavitt model of organization and organizational change provides a good point of departure for inquiry into informing issues in organizations. The same applies to the prescript on a multilevel analysis. In addition, a strong emphasis is placed on human communication, which is viewed exclusively through the prism of the anthropomorphic Shannon-Weaver (1949) model. Indeed, this model is the backbone of the entire informing science framework. Before turning to appraising this model, let me list some other important characteristics of informing science. The emphasis on communication is somewhat overwhelming as it obscures to some extent distinctions between communication and ISs. While the emphasis on communication has merits of bringing to the fore information, the often neglected aspect in the mainstream IS research, it is unclear why should inquiry give up the distinctions between communication and ISs. In keeping with traditions of human communication theory, communication is to be considered a particular aspect of or process in organization. Similarly, in the IS field IS is usually conceptualized as a separate whole that consists of data, IT and procedures, and which delivers processed (organized, "meaningful”) data. ISs are used for various purposes, including communication. It is not clear why informing science does not use explicitly this concept of IS and integrates it with the chosen model of communication instead of bringing the model of communication and the implicit concept of IS into a parent-child relationship. Also, the goal of effective informing of clients can be equally reached if the relationship between system developers and users is placed in a service providercustomer model rather than in the communication model. In such a model, communication could still play a big role, but other aspects would be accounted for as well (budget, technology tradeoffs, organizational context, vendor management, change management, etc.). 
Erasing the distinction between communication and ISs has led to another questionable choice: face-to-face communication is undistinguishable from mediated communication, and IT becomes any thing and any symbolic entity. For example, Gackowski (2005) explicates that IT includes voice, personal and impersonal contacts (e.g., displays of merchandise) (p. 119). On the other hand, although IT is conceived so broadly, automated ISs are not listed as a kind of IT or IS. This choice locks out a whole slate of important systems, such as those supply chains, knowbots, software agents in online exchanges, control rooms in automated factories, and software intensive systems for the production in mass media, aircrafts and weaponry. This reduction is consequent to the driving purpose of informing human clients, but it runs (again) counter the commonly accepted definition of IS and the real world ISs.

\section{Limitations of Shannon and Weaver's Model}

Shannon and Weaver's (1949) mathematical model of communication (further, the model) makes the backbone in the informing science works discussed above (Cohen, 1999; Gackowski, 2005: Roussev \& Rousseva, 2004). In the larger field of ISs, the model has achieved prominence with the proliferation of communication systems in the 1980s. According to Putnam, Phillips, and Chapman (1996), the model had for long been the most frequently used model in the study of organizational communication. In the area of organization theory, information processing view of organization (Galbraith, 1973) has most directly applied the model. It could be that the model has had the large acceptance because of its intuitive character: it outlines a common process of communication that occurs across contexts - in interpersonal as well as in mass communication, in face-to-face as well as in mediated communication, and in classical commercial publishing as well as in one-to-many publishing on the Internet (Web sites, blogging).

The trade-off side of the model, however, is paramount. First of all, the interpretation of the model in social sciences, including the IS field, is more arbitrary than formalized. ${ }^{1}$ The ultimate roots lie in the shift of meanings that accompanied the importation of the model into social sciences. Specifically, sender and receiver have became social actors that can communicate face-toface or via some communication technology (e.g., the telephone). Signal has become message or information, and channel is whatever medium happens to enable the exchange of messages between the sender and receiver (e.g., the air for transferring verbal messages and a computer network for email messages). In addition, noise or entropy is any loss in a message-in the content, clarity, etc. Being social actors rather than machines, both the sender and the receiver have become imbued with intention: the sender intends to send ("communicate”) a certain message (information), and the receiver intends to receive the message (information) and act upon it. The shift in meanings of the core concepts in the original model also applies to "information," the key concept. No longer representing the compensation for the entropy caused by the communication channel, information is now given the role of reducing entropy that is relocated into the receiver's mind. Entropy is conceived as uncertainty-a shortage in cognition or simply ignorance, which exists prior to an act of communication. The receiver misses data or lacks knowledge, and information "comes" to him from the sender to add to his cognition, and thereby reduce his uncertainty.

The "upgrades" of the original model discussed above are of such magnitude that the resulting model qualifies indeed as a new one, deserving to be called "anthropomorphized ShannonWeaver model.” The initial arbitrariness at the point of importing the model was expanded to incorporate axioms behind the anthropomorphized variant. For example, uncertainty is approached from a deterministic perspective, which appears to be connected with an assumption that information is an object transferable from person to person (see Putnam et al., 1996). Taking again our example of the utility company and its ERP system, it is apparent that a supervisor cannot know how much time an hourly worker has put in (uncertainty) before collecting data on the hours the 
worker has logged (information). Then, a clerk tabulates a worker's hours (information) in an electronic spreadsheet and transfers this electronically (communication) to the supervisor for online approval. The anthropomorphized model works well in these examples of simple informing, where information poses in its simplest form of data. However, as the discussion on IVO above demonstrated, information also comes in the more complex forms of meaning and knowledge.

Consider the perspective of a developer of the ERP system in the utility company case. This system supports data entry, reporting, and approval of work hours. I would argue that it is unlikely that the developer can identify the entire domain of uncertainty associated with the system's specifications, even with a full participation of users. The scope of uncertainty includes the content and format of data records and of reports, manners in which the records and reports will be interpreted by individual users, design of screens (the navigation and esthetics characteristics desired by different users), and the system response time. The last item is complex in itself since in today's distributed, multi-tiered system architectures the system response time is a compound of response times of a database server, application server, and Web server, plus transfer times between these servers, minus slowdowns due to records locking, load imbalance, and network throughput, and so on. It is also true that the historical aspect adds to uncertainty. For example, users may not know what they really need or if what they thought they needed is what they really need unless they try the system. Foresight is a young parent of learning, and hindsight is its mature parent. If the pool of uncertainty accompanying systems design were determinate, we would have much better ISs in general and ERP systems in particular with a less dramatic failure rate than it is (the estimates of failure of ERP systems vary, but most of them put the rate above $50 \%$; e.g., IT Cortex 2001; Karaian, 2005).

The discussion above suggests that deterministic concepts of uncertainty may not suffice. Enter complexities of information taken at the level of meaning. To what extent do technologists and end users understand each other's language? Do the same words trigger same meanings in their minds? Do they reside in comparable organizational contexts that make impacts on the creation of meaning (e.g., comparable on the IT-related goals and on understanding of business and timing priorities)? What are the effects of contextual factors, individual psychology (personal, cognitive), and situational factors (e.g., intentions and other factors that are captured in Searle's (1979) theory of speech acts)?

Realistic answers to these questions or the lack thereof are likely to underline difficulties of the deterministic approach to uncertainty. The anthropomorphized Shannon-Weaver model is incapable of dealing with the complexities of communicating meaning that pertain to both the sender and receiver because the model suits merely data transfer scenarios and focuses on the sender side (see Putnam et al., 1996).

In addition to being inherently imperfect and so coupled with uncertainty, information can even generate uncertainty. In their critique of the applications of Shannon and Weaver's model, Huber and Daft (1987) have proposed that "information can increase uncertainty if it contradicts previously believed truths” (p. 156). Gackowski’s (2005) critical remark cited above is in agreement with this proposition, in contrast to other informing science works cited above. IVO is also agreeable, and it takes this proposition a step further by proposing a concept of "spiral of uncertainty" (Travica, 2006). In brief, "spiral of uncertainty" relates information (in the broad sense), uncertainty and time, and it proposes that information can reduce uncertainty with regard to the past, while it can simultaneously create uncertainty with respect to the future. For example, by learning that a worm infected corporate mail servers (information), a network administrator resolves the uncertainty regarding the state of the servers, while this realization can prompt him to question the breadth and depth of damage (uncertainty). Whereas Shannon and Weaver's original model operated with a definitive resolution of finite uncertainty, organizational and social worlds are 
rather like flows in which the past, present and future can only analytically be separated. Living with uncertainty indeed is the modus vivendi in the world of ours that behaves as a highly complex system. ${ }^{2}$ This world has been intellectually constructed through contributions that lie on the other side of Cartesian-Newtonian certainty and predictability, such as Einstein's theories of relativity, Heizenberg's principle of uncertainty, Saussure's linguistics, Wittgenstein's language games, and contemporary philosophy (e.g., Austin, 1962; Rorty, 1982) and sociology (e.g., Giddens, 1979, 1984; Latour, 2005). Unfounded optimism or info-optimism characterizes the expectation that information is exclusively the means of resolving uncertainty in such a world.

Finally, the anthropomorphic Shannon-Weaver model is being abandoned among communication scholars. In the field of organizational communication, the long reign of this model and its underlying modernist paradigm has recently been challenged by the naturalistic (cultural) and critical (political) perspectives (Redding \& Tompkins, 1988). The modernist view portrays organization as a purposeful instrument for achieving certain goals is no longer considered adequate. The perspective change has also been reflected in cardinal reviews of organizational communication research (cf. Jablin \& Putnam, 2001; Jablin, Roberts, Putnam, \& Porter, 1987). In their taxonomy of communication metaphors, Putnam and colleagues (1996) use the term "conduit model” for Shannon-Weaver model in order to point out the assumed model of organization. The authors argue that the conduit model conceives organization as a container in which transmissions of messages take place. Communication within this container is "linear and effortless," and "miscommunication occurs when no information is received or when the information received is not what the sender intended" (Putnam et al., 1996: 380). Cognate to the conduit metaphor are the metaphors of lens and linkages. The lens metaphor focuses on transmission characteristics (routing, searching, filtering, gate-keeping, distorting information). The configuration and usage of transmission channels ("communication networks") is the subject of the linkages metaphor. The contemporary study of organizational communication exhibits a radical departure from these metaphors (more further below).

In brief, the use of Shannon and Weaver's (1949) mathematical model of communication in social sciences is bound to arbitrary definitions of key terms and their relationships, deterministic assumptions, a focus on data and the sender as opposed to problems of meaning that occur at both ends of communication, and info-optimism regarding challenges of uncertainty. Students of organizational communication increasingly abandon the model. Given these circumstances, it is questionable if the model is the best guide for meeting the prudent goal of informing science to effectively inform clients.

\section{Similarities and Differences between IVO and Informing Science}

The discussion in the previous sections has indicated numerous connections between informing science and IVO. These are shown in Table 2. In particular, both IVO and informing science take an interdisciplinary and integrationist approach, have a practitioner/service orientation, exhibit an information, organization, and communication focus, and apply multi-level analyses.

On the difference side, IVO is more pronounced in terms of reference disciplines, communication contexts, distinctions between communication, IS and IT, and differences between mediated and face-to-face communication. Also, IVO adds a theoretical academic orientation to the practitioner's one. While service to users of information, IT and IS motivates IVO as much as service to information users motivates informing science, IVO balances this with the goal of advancing theory of ISs. It could be argued that the goal of "effective informing" put forward in the definition of informing science is not a criterion for defining an area of academic study but rather is a consequence of a practitioner's and consulting approach. ISs can be more or less effective, but this 
does not make or break the fact that they are ISs. Once a system is understood (the contribution of theory), effectiveness goals can be addressed.

IVO operates with a broader concept of information, organization and communication, and explicitly addresses IT in its various functional and historical forms. In contrast, informing science puts a stronger emphasis on human communication than IVO. Finally, analysis in IVO involves individual, group, organizational, and interorganizational levels, and adds the issues of systems adoption to the list of otherwise overlapping IS-related issues. As for organizational issues, IVO has somewhat a broader coverage that accounts for thus far addressed issues in informing science. For example, Gackowski's (2005) economic analysis fits into the rubric of infoeconomics (although relations between the two in terms of premises and results of analysis is a different topic that cannot be addressed in this article).

Table 2. Informing Science and Information View of Organization

\begin{tabular}{|c|c|}
\hline Informing Science & Information View of Organization \\
\hline Interdisciplinary integrationist position & $\begin{array}{l}\text { Interdisciplinary integrationist position, where the } \\
\text { core reference disciplines are organiza- } \\
\text { tion/management theory and cognitive theory }\end{array}$ \\
\hline Practitioner focus with service orientation & Practitioner/service and academic orientation \\
\hline $\begin{array}{l}\text { Information focus (data focus and some } \\
\text { attention to meaning (“information”)) }\end{array}$ & $\begin{array}{l}\text { Information focus based on complex model of in- } \\
\text { formation (data, meaning, knowledge) }\end{array}$ \\
\hline $\begin{array}{l}\text { Broadening spectrum of information tele- } \\
\text { ology (reduction of uncertainty, increase of } \\
\text { uncertainty) }\end{array}$ & $\begin{array}{l}\text { Broad spectrum of information teleology } \\
\text { (Spiral of uncertainty) }\end{array}$ \\
\hline IT implicit in the notion of delivery & $\begin{array}{l}\text { IT explicit and treated broadly-from electronic to } \\
\text { paper }\end{array}$ \\
\hline $\begin{array}{l}\text { Concern for organizational context using } \\
\text { Leavitt's (1965) model }\end{array}$ & $\begin{array}{l}\text { Strong concern for organizational context, aspects } \\
\text { represent major views of organization and different } \\
\text { philosophical paradigms }\end{array}$ \\
\hline $\begin{array}{l}\text { - Strong concern for human communica- } \\
\text { tion regardless context, goal to inform cli- } \\
\text { ents } \\
\text { - Shannon \& Weaver's (1949) model ex- } \\
\text { clusive } \\
\text { - Face-to-face and mediated communica- } \\
\text { tion undifferentiated } \\
\text { - Communication undifferentiated from IS } \\
\text { and IT }\end{array}$ & $\begin{array}{l}\text { - Concern for human communication in the indi- } \\
\text { vidual, group, inter-unit, and interorganizational } \\
\text { context } \\
\text { - Different communication models, stress on mean- } \\
\text { ing and knowledge on the receiver's side } \\
\text { - Face-to-face and mediated communication clearly } \\
\text { differentiated } \\
\text { - Communication, IS and IT clearly differentiated }\end{array}$ \\
\hline $\begin{array}{l}\text { Multi-level analysis of informing models' } \\
\text { use, design, and creation of new designs; } \\
\text { analysis of economic aspects }\end{array}$ & $\begin{array}{l}\text { Multi-level analysis (individual, group, organiza- } \\
\text { tional, interorganizational) intersected with issues } \\
\text { of IS design, adoption, use, and evaluation }\end{array}$ \\
\hline
\end{tabular}

In summary, there are fundamental similarities as well as certain differences between informing science and IVO. Typically, IVO is broader and more inclusive, which is particularly visible in the way IVO conceives information, IT, organization and communication. 


\section{Expanding Informing Science}

Informing science is new, evolving, and open to change and self-improvement (cf. Cohen, 1999). IVO is even a newer framework that developed independently of informing science. I tried to show in the discussion above that there are significant overlaps between the two frameworks. ${ }^{3}$

Indications of the directions in expanding informing science are presented in Table 2.

Informing science could benefit from pronouncing clearly the differences between communication, IS and IT. Also, explanatory power could be raised by bringing IT to the fore and dealing with it in a detail-rich way as it has been attempted in case studies based on IVO. It is also important to clarify the position with regard to ontology of IT. Neither the mainstream IS field nor the organizational communication field provide support to the thesis that the concept of IT includes human voice or interpersonal contacts (Gackowski, 2005). IVO proposes that IT be conceived of in terms of material artifacts designed for manipulating data, and that this IT is part of ISs. Informing science might want to broaden this definition with institutional or some other elements. In any case, IT needs to be distinguished from definitional elements of human communication. Otherwise, informing science may turn out to be a stream of research within the communication rather than the IS field.

Another line of conceptual differentiation concerns the need to separate face-to-face and mediated communication. This separation is connected with bringing up the IT perspective since mediation comes from using IT in communication. Furthermore, it might be instructive to examine possibilities for strengthening a theoretical orientation of informing science. While providing service to users of information is a prudent goal that IVO shares, the goal would be more achievable with aid of adequate theory.

Broadening the concepts of information, organization and communication may be another area for informing science to explore. In the preceding discussion, I tried to elaborate on shortcomings of the Shannon and Weaver's (1949) model of communication as it has been used in social sciences. Also, I pointed to the dependence between models/metaphors of communication and ontology of organization. The rationale of this discussion is that informing science may be truer to its key goal if it anchors itself into broader conceptualizations of communication and organization.

The field of organizational communication, for example, provides alternatives to the conduit model. As Putnam and colleagues (1996) elaborate in their taxonomy, one option is the metaphor of performance (communicative performance). Advocated by Weick (1979), the performance metaphor focuses on action, reaction, interpretation, equivocality, reflection and sense making in the interpersonal context. Senders and receivers are accounted for, but in a rather non-linear fashion, and the receiver's side is prominent. The performance metaphor does not assume that organization is a given entity (structure, culture, etc.). Instead, organization is an ongoing process of organizing that unfolds via communication. Organizations present contexts of equivocality where people act and then reflect on their actions to make sense of organizing (Putnam et al., 1996).

The symbols metaphor focuses on organizational culture embodied in stories, metaphors, rituals, irony and other cultural artifacts (Czarniawska-Joerges, 1992). Thus, cultural artifacts and behaviors, including interactions of purposive rational informing, communicate key organizational beliefs to the "receiver." This metaphor implies that organization is created and maintained via the processes of constructing shared meanings, or by "fostering and developing (...) shared interpretive schemes that create and recreate (...) meaning” (Morgan, 1986: 135). In other words, what matters is a connotative cultural meaning rather than a denotative informing content.

Next is the metaphor of voice, which renders communication in a political light, by concentrating on who, when, and how an option can be voiced. (Deetz, 1992). Since some voices are expressed 
and others are suppressed, it is important to know what cannot be sent via communication channels and not only what is sent. Also, information accuracy (message fidelity in the conduit model) becomes secondary because information typically has a political bias-communication is "distortion” (Redding \& Tompkins, 1988). This thesis strikes directly into the plexus of the model of organization as a rational instrument/machine that fits with the conduit metaphor of communication. The political metaphor embraces a model of organization in which self interest paints each aspect. Self-interest agendas range from protecting a "turf" that everyone has to imposing domination over others. Interests paint rationality as well, and so rationality of any act (including informing one) is inherently political (Morgan, 1986, p. 195).

Finally, the metaphor of discourse makes language the subject of study, covering many topical areas, such as speech acts, language games, conversational analysis, dialogue, and properties and patterns of interaction (see Putnam et al., 1996: 391-394). Thus, the core medium of communication-language - constitutes the domain of research problems. The organization model this metaphor espouses is the one in which organization is constructed through the use of language. But language is not just a neutral tool for encoding and decoding messages/information as the conduit metaphors suggests. As the preceding metaphors of communication suggest, language is also the means to political and cultural ends.

The analysis of the relationship between IVO and informing science also revealed that the latter prefers a deterministic approach to challenges of uncertainty. This is coupled with an expectation that information always reduces uncertainty, which appears as unwarranted optimism in this complex and probabilistic world. Instead of succumbing to such info-optimism, informing science may do better if it takes information for what it is-both a creator and reducer of uncertainty. Then, energy can be committed to more realistic goals of dealing with the world in which uncertainty is a modus vivendi. The goal shift may help to realize that uncertainty is the engine of movement, change and development without which the knowledge development would stop. It may even be useful to create uncertainty in order to mobilize the potential for creativity in organization members, as the Japanese executives use to do by uttering ambiguous statements (Nonaka \& Takeuchi, 1995).

One way of assisting informing science in nearing to the changes proposed above is by the means of the Journal of Information, Information Technology, and Organizations (JIITO) that was recently launched. The mission and editorial policy of this publishing outlet complies with basic premises of IVO. A notable difference is that JIITO is supposed to cover a broader range of organizational contexts (not only firms and non-profit institutions, but communities as well). Empirical and conceptual contributions of JIITO are expected to demonstrate advantages of broadening the horizons in investigating the ways of informing information clients in organized contexts. Specifically,

"JIITO encourages articles that use rich, detailed accounts of information and IT" and "empirical studies that explain how organizations cope, prosper, change, fail with respect to using, managing, designing and adopting information systems. In the conceptual realm, JIITO encourages articles that take a critical look at advent, genesis and uses of models that have influenced IS research for considerable time.” (JIITO, 2005)

As for the influences of informing science on IVO, the demonstrated significant overlap between the two frameworks with regard to goals, premises and topics lay the ground for introducing the label "Informing View of Organization,” which can be used in parallel with the original label. 


\section{Summary}

This article discussed premises, goals, and the scope of IVO (Travica, 2003, 2004, 2005a, 2005b, 2006) and of informing science (Cohen, 1999; Gackowski, 2005; Roussev and Rousseva, 2004). Each approach was defined and their main conceptual characteristics were discussed. The IVO approach was also illustrated with evidence from several case studies and an ongoing investigation. Further, informing science was critically appraised, and its similarities with and differences from IVO analyzed. The article identified several ways in which IVO can contribute to advancing informing science.

\section{Notes}

(1) Note that Shannon and Weaver are not responsible for later deviations of their model, except perhaps for the choice of the keyword. The model has been widely used within the appropriate domains of application (e.g., telephone networks). However, Shannon admitted having a regret for using the term "information" to signify the notion of negative entropy. Even at their time, the term was associated with a plethora of meaning. "Information" had a formalized meaning in information theory developed under the auspices of the $19^{\text {th }}$ century thermodynamics, became involved in a wide circulation with the advent of daily press, radio and TV, and was used in biology and some other areas.

(2) Even in the modern telephone systems, which descended from the telephone networks Shannon and Weaver studied, the theory of chaos appears to be a necessary addition in network management. These networks have been transformed into highly complex, dynamic systems that call for new theories and analytical models.

(3) Drawing on accustomed meanings of the terms "science" ("a department of systematized knowledge as an object of study") and "framework" ("a basic conceptual structure, as of ideas"), I prefer to use the term "informing science framework" rather than "informing science." (Merriam-Webster Online, 2005)

\section{References}

Austin, J. (1962). How to do things with words. Oxford, UK: Clarendon.

Barley, S. (1986). Technology as an occasion for structuring: Evidence from observations of CT scanners and the social order of radiology departments. Administrative Science Quarterly, 31, 78-108.

Barley, S. (1990). The alignment of technology and structure through roles and networks. Administrative Science Quarterly, 35, 61-103.

Brynjolfsson, E., \& Hitt, L. (1998). Beyond the productivity paradox. Communications of the ACM, 41(8), 49-55.

Castells, M. (1996). The rise of the network society. Malden, MA: Blackwell.

Carr, N. (2004). IT doesn't matter. HBR, May.

Ciborra, C. (Ed.). (1996). Groupware and teamwork: Invisible aid or technical hindrance? Chichester: John Wiley \& Sons.

Clegg, S., Hardy, C., \& Nord, W. (Eds.). (1996). Handbook of organization studies. London: SAGE.

Clegg, S., \& Hardy, C. (1996). Organizations, organization and organizing. In S. Clegg, C. Hardy, \& W. Nord (Eds.), Handbook of organization studies (pp. 1-28). London: SAGE.

Cohen, E. (1999). Reconceptualizing information systems as a field of the transdiscipline informing science: From ugly duckling to swan. Journal of Computing and Information Technology, 7(3), 213-219.

Crozier, M. (1967). The bureaucratic phenomenon ( $2^{\text {nd }}$ ed.). Chicago, IL: University of Chicago Press. 
Czarniawska-Joerges, B. (1992). Exploring complex organizations: A cultural perspective. Newbury Park: SAGE.

Davenport, T., \& Prusak, L. (1997). Information ecology: Mastering the information and knowledge environment. New York-Oxford: Oxford University Press.

Davidow, W. H., \& Malone, M. S. (1992). The virtual corporation. New York: Harper.

Deetz, S. (1992). Democracy in an age of corporate colonization: Developments in communication and the politics of everyday life. Albany, NY: State University of New York Press.

Eysenck, M., \& Keane, M. (1995). Cognitive psychology: A student handbook. Jove, UK: Lawrence Erlbaum Associates.

Gackowski, Z. (2005). Informing systems in business environments: A purpose-focused view. Informing Science Journal, 8, 101-122. Retrieved from http://inform.nu/Articles/Vol8/v8p101-122Gack.pdf.

Galbraith, J. (1973). Designing complex organizations. Reading: Addison-Wesley.

Giddens, A. (1979) Central problems in social theory: Action, structure and contradiction in social analysis. London: Macmillan.

Giddens, A. (1984) The constitution of society. Outline of the theory of structuration. Cambridge: Polity Press.

Hammer, M, \& Champy, J. (1993). Reengineering the corporation: A manifesto for business revolution. New York: HarperBusiness.

Handy, Charles. (1993) Understanding organizations. Oxford: Oxford University Press.

Hatch, M. J. (1997). Organization theory: Modern, symbolic, and postmodern perspectives. Oxford-New York: Oxford University Press.

Heckscher, C., \& Donnellon, A. (Eds.). (1994). The post-bureaucratic organization: New perspectives on organizational change. Thousand Oaks: SAGE.

Huber, G., \& Daft, R. (1987). The information environments of organizations. In F. Jablin, L. Putnam, K. Roberts \& L. Porter (Eds.), Handbook of organizational communication: An interdisciplinary perspective (pp. 130-164). Newbury Park, CA: SAGE.

Iivary, J., \& Lyytinen, K. (1999). Research on information systems development in Scandinavia: Unity in plurality. In W. Currie \& B. Galliers, Rethinking management information systems (pp. 57-100). Oxford: University Press.

IT Cortex. (2001). Statistics over IT projects failure rate. Retrieved from http://www.itcortex.com/Stat_Failure_Rate.htm\#The\%20Robbins-Gioia\%20Survey\%20(2001) .

Jablin, F. M., \& Putnam, L. L. (Eds.). (2001). The new handbook of organizational communication: Advances in theory, research, and methods. Thousand Oaks, CA: Sage.

Jablin, F., Roberts, K., Putnam, L., \& Porter, L. (Eds.). (1987). The handbook of organizational communication, Newbury Park, CA: SAGE.

JIITO. (2005). Editorial statement. Accessed: 11/25/2005. Available: http://www.jiito.org/statement.html

Karaian, J. (2005). CFO Europe. Accessed: 11/28/2005. Available at http://www.cfoeurope.com/displayStory.cfm/3929294

Kiesler, S., Siegel, J., \& McGuire, T. W. (1984). Social psychological aspects of computer-mediated communication. American Psychologist, 39(10), 1123-1134.

Latour, B. (2005). Reassembling the social: An introduction to actor-network- theory. Oxford University Press.

Leavitt, H. (1965). Applied organizational change in industry - Structural, technological and humanistic approaches. In J. March (Ed.), Handbook of organizations (pp. 1144 - 1170). Chicago: Rand McNally. 
Malone, T., \& Crowston, K. (1994). The interdisciplinary study of coordination. Computing Surveys, 26(1), $87-119$.

Majchrzak, A., Beath, C., Lim, R., \& Chin, W. (2005). Managing client dialogues during information systems design to facilitate client learning. MIS Quarterly, 29(4).

Mason, R., \& Mitroff, I. (1973). A program for research in management information systems. Management Science, 19(5), 475-485.

Morgan, G. (1986). Images of organization. Newbury Park: SAGE.

Merriam-Webster Online. (2005). Dictionary units “science” and “framework.” Available at http://www.mw.com/dictionary/

Nonaka, I., \& Takeuchi, H. (1995). The knowledge creating company: How Japanese companies create the dynamics of innovation. New York: Oxford University Press.

Nunamaker, J., Briggs, R., Mittleman, D., Vogel, D. \& Pierre, B. (1996/7). Lessons from a dozen years of group support systems research: A discussion of lab and field findings. Journal of Management Information Systems, 13(3), 163-207.

Orlikowski, W. (1992). The duality of technology: Rethinking the concept of technology in organizations. Organization Science, 2(3), 398-427.

Orlikowski, W. \& Barley, S. (2001). Technology and institutions: What can research on information technology and research on organizations learn from each other? MIS Quarterly, 25(2), 145-65.

Orlikowski, W. \& Iacono, S. (2001). Research commentary desperately seeking the "IT" in research - A call to theorizing the IT artifact. Information Systems Research, 12(2), 121-134.

Peters, T. (1992). Liberation management: Necessary disorganization for the nanosecond nineties. New York: Alfred A. Knopf.

Pfeffer, J. (1981). Power in organizations. Marshfield, MA: Pitman Publishing Inc.

Putnam, L., Phillips, N., \& Chapman, P. (1996). Metaphors of communication and organization. In S. Clegg, C. Hardy, \& W. Nord (Eds.), Handbook of Organization Studies (pp. 375-408). London: SAGE.

Redding, W. C., \& Tompkins, P. K. (1988). Organizational communication—past and present tenses. In G. M. Goldhaber \& G. A. Barnett (Eds.), Handbook of organizational communication (pp. 5-33). Norwood, NJ: Ablex.

Roach, S. S. (1987). America's technology dilemma: A profile of the information economy. Morgan Stanley Special Economic Study, April.

Rorty, R. (1982).Consequences of pragmatism. Minneapolis, MN: University of Minnesota Press.

Roussev, B., \& Rousseva, Y. (2004). Software development: Informing sciences perspective. Journal of Issues in Informing Science and Information Technology, 1, 237-245. Available at http://articles.iisit.org/040rouse.pdf

Sarker, S. \& Lee, A. (2000). Using a case study to test the role of three key social enablers in ERP implementation. In S. Ang, H. Krcmar, W. Orlikowski, P. Weill, \& J. I. DeGross (Eds.), Proceedings of the 21st International Conference on Information Systems (pp. 414-425), December 10-13, 2000 Brisbane, Australia.

Searle, J. (1979). Expression and meaning: Studies in the theory of speech acts. Cambridge, MA: Cambridge University Press.

Shaila, M., \& Saunders, C. (1995). Group support systems: An organization development intervention to combat groupthink. Public Administration Quarterly, 19(2), 193-217.

Shannon, C., \& Weaver, W. (1949). The mathematical theory of communication. Urbana, IL: University of Illinois Press. 
Shepherd, M., Briggs, R., Reining, B. A., \&Yen, J. (1995). Social loafing in electronic brainstorming: Invoking social comparison through technology and facilitation techniques to improve group productivity. Proceedings of the Twenty-Eighth Hawaii International Conference on Systems Sciences, 4, 523532.

Snyder, H., \& Davenport, E. (1997). Costing and pricing in the digital age: A Practical guide for information services. New York: Neal-Schuman Publishers.

Thietart, R., \&. Forgues, B. (1995). Chaos theory and organization. Organization Science, 6(1), 19-31.

Travica, B. (1999). New organizational designs: Information aspects. Stamford: Ablex.

Travica, B. (2003). Information view of organizations: Contextualizing technology - Technologizing context. Proceedings of 2003 AMCIS, August 4-6, 2003, Tampa, FL. Nominated for the Best Papers Award.

Travica, B. (2004). Organizations as information processes. In J. Akoka (Ed.), Proceedings of the Pre-ICIS Conference, Washington, D.C., December 2004.

Travica, B. (2005a). Information politics and information culture: Case Study. Informing Science Journal, 8, 211-245. Available at http://inform.nu/Articles/Vol8/v8p211-244Travica.pdf

Travica, B. (2005b). Information view of organization. Journal of International Technology and Information Management, 14, 1-20.

Travica, B. (2006). Information view of organization. [forthcoming].

Turoff, M., Hiltz, S. R., Bahgat, A., \& Rana, A. (1993). Distributed group support systems. MIS Quarterly, 17(4), 399-417.

Weber, M. (1946). Essays in sociology. Oxford University Press.

Weick, K. (1979). The social psychology of organizing. Reading, MA: Addison-Wesley.

Westwood, R. \& Clegg, S. (Eds.). (2003). Debating organization: point-counterpoint in organization studies. Malden, MA: Blackwell.

Zuboff, S. (1984). In the age of the smart machine: The future of work and power. Basic Books.

\section{Biography}

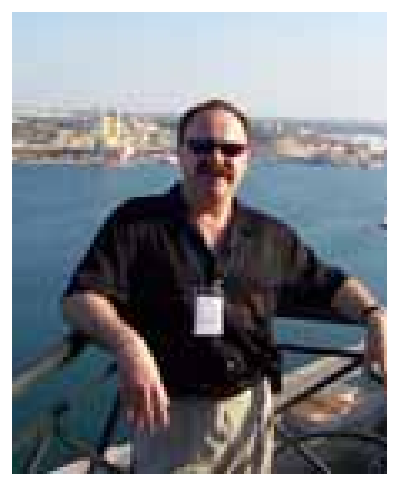

Bob Travica teaches information systems at University of Manitoba, Canada. He taught at Indiana University, studied in the United States, lived and worked in Europe and Latin America. Bob metamorphosed through several careers including journalism and software development. His research interests include information view of organization, new organizational designs, e-commerce, and international issues. 